recommendations on active ingredient, dose units, or formulations for a specific age group-for example, quinolones in children and xylometazoline $1 \%$ formulations for babies.

The proportion of off label prescriptions was highest for 1-2 year olds (68 $791(17.9 \%, 17.8 \%$ to $18.1 \%)$ prescriptions) and lowest for 7-11 year olds (40 539 (10.5\%, $10.4 \%$ to $10.6 \%)$ prescriptions).

Of the $181914(8.8 \%)$ prescriptions for topical treatments of the skin, eye, or ear, 116060 (63.8\%, $63.6 \%$ to $64.0 \%$ ) were off label. The active ingredients of the most commonly prescribed systemic off label drugs are shown in the table.

Off label prescribing was common for cardiovascular drugs $(3646 ; 55.2 \%, 53.9 \%$ to $56.4 \%)$, drugs for genitourinary disorders $(1869 ; 48.5 \%, 46.9 \%$ to $50.1 \%)$, anti-inflammatory agents $(7194 ; 45.0 \%, 45.2 \%$ to $46.0 \%)$, antidepressants $(246 ; 36.6 \%, 33.0 \%$ to $40.4 \%)$, and antidementia $(11 ; 34.4 \%, 18.6 \%$ to $53.2 \%)$, antiepileptic $(932 ; 14.2 \%, 13.3 \%$ to $15.0 \%)$, and antipsychotic drugs $(54 ; 10.2 \%, 7.8 \%$ to $13.2 \%)$.

\section{Comment}

We found that $13.2 \%$ of prescriptions for a representative group of children in primary care in Germany were off label. Although we could not detect off label use due to dosage or indication with this database, the proportion of prescriptions that were off label was similar to that in much smaller studies that analysed dosage and diagnoses. ${ }^{4}$ Our data show that efforts to improve the quality of pharmacotherapy in children should not exclude widely marketed and firmly established drugs.

We thank Christoph Meisner, Institute for Medical Information, University of Tübingen, for statistical analysis and Doris Merz, Allgemeine Ortskrankenkasse, Baden-Württemberg, for help with the database.

Contributors: MS, KM, and CG designed the study. PS provided access to Allgemeine Ortskrankenkasse, BadenWürttemberg, and gave information concerning drug prescription patterns in outpatients. HS matched the file with prescription data to another database including the anatomical, therapeutic, and chemical classification of the World Health Organization. BK and HM provided computer based analyses. RB designed the study, coordinated study procedures, determined licence status of prescriptions, analysed the results, and wrote the paper. CG is guarantor.

Funding: KM and CG are supported by the German Bundesministerium für Bildung und Forschung, grant 01EC 0001, and the Ministerium für Wissenschaft und Kunst, BadenWürttemberg, Germany. MS is supported by the Robert Bosch Foundation, Stuttgart.

1 Conroy S, Choonara I Impicciatore P, Mohn A, Arnell H, Rane A, et al. Survey of unlicensed and off label drug use in paediatric wards in European countries. BMJ 2000;320:79-82.

2 Collier J. Paediatric prescribing: using unlicensed drugs and medicines outside their licensed indications. Br J Clin Pharmacol 1999;48:5-8.

3 Turner S, Nunn AJ, Fielding K, Choonara I. Adverse drug reactions to unlicensed and off-label drugs on paediatric wards: a prospective study. Acta Paediatr 1999:88:965-8.

4 McIntyre J, Conroy S, Avery A, Corns H, Choonara I. Unlicensed and off label prescribing of drugs in general practice. Arch Dis Child 2000;83:498-501.

5 Chalumeau M, Treluyer JM, Salanave B, Assathiany R, Cheron G, Crocheton N, et al. Off label and unlicensed drug use among French office based paediatricians. Arch Dis Child 2000;83:502-5.

(Accepted 2 January 2002)

\title{
Unlicensed and off label drug use by children in the community: cross sectional study
}

\author{
Eric Schirm, Hilde Tobi, Lolkje T W de Jong-van den Berg
}

Editorial by Banner and $p p 1311,1313$

Department of Social Pharmacy, Pharmacotherapy and Pharmacoepidemiology, Groningen University Institute for Drug Exploration, University of Groningen, Groningen,

Netherlands Eric Schirm research pharmacist Hilde Tobi assistant professor Lolkje T W de Jong-van den Berg professor

Correspondence to: L T W de Jongvan den Berg l.t.w.de.jong-van.den. berg@farm.rug.nl
Studies in various hospital settings showed that many drugs taken by children either are not licensed or are used outside the terms of the product licence. ${ }^{1-3}$ Information on the extent of paediatric labelling of drugs taken by children in the community is, however, limited and based on small study populations. ${ }^{45}$ We studied drugs taken by children in the community, based on the pharmacy records of prescriptions from both general practitioners and outpatient departments. We aimed to determine the number of prescriptions for unlicensed drugs for children in the community and to investigate paediatric labelling of all drugs with a product licence to determine the extent of off label use.

\section{Participants, methods, and results}

In the Netherlands people commonly register with one pharmacy, from which they obtain their drugs, including those prescribed as outpatients. Excluded are drugs used during hospital stays and those bought over the counter. We obtained our data on dispensing from the InterAction database, which covers part of the northern Netherlands.

We selected all prescriptions for children aged 0-16 years in 2000. Dutch pharmacies are allowed to prepare their own formulations and to modify commercial preparations. These pharmacy based preparations are exempt from licensing, and we classified them as unlicensed. For each prescription of a licensed drug (all remaining prescriptions) we examined the official licence information-the summary of product characteristics-in detail. We determined whether the summary mentioned use in children and, if so, the minimum age. When age was unspecified we set it at a minimum of 0 years. If use in children was not mentioned or was advised against without an indication of age, we set the minimum age at 18 years. We considered that a drug with a product licence was used according to the label if the summary of product characteristics stated that it could be used in children, and if the child was of the minimum age for use or older; otherwise we considered the drug was used off label. As information about indications was not available, we were not able to distinguish between different indications in the summary.

We analysed 68019 prescriptions for 19283 children aged 0-16 years. General practitioners were responsible for $56961(83.7 \%)$ of the prescriptions; the remainder came from specialists. Unlicensed drugs amounted to $16.6 \%$ (11 288) of the total pre- 
Information given in summary of product characteristics of drugs prescribed to children in the community in the Netherlands

\begin{tabular}{|c|c|c|c|}
\hline Category & Example & $\begin{array}{c}\text { No }(\%) \text { of summaries } \\
(n=1421)\end{array}$ & $\begin{array}{l}\text { No }(\%) \text { of prescriptions } \\
(n=56731)\end{array}$ \\
\hline Child mentioned with indication of age & Children 2-5 years: $10 \mathrm{mg}$ per day & $653(46.0)$ & $32180(56.7)$ \\
\hline Child not mentioned & Only "patients" in general mentioned & $302(21.3)$ & $11688(20.6)$ \\
\hline Child mentioned without indication of age & Children: $0.75 \mathrm{mg} / \mathrm{kg}$ in twice daily & $280(19.7)$ & $11108(19.6)$ \\
\hline Child mentioned but advised against use for all ages & $\begin{array}{l}\text { Should not be used in children; safety and } \\
\text { efficacy have not been established in children }\end{array}$ & $140(1.0)$ & $1328(2.3)$ \\
\hline Child mentioned and age estimated on basis of description & Adults and older children: $10 \mathrm{mg}$ per day & $19(1.3)$ & $219(0.4)$ \\
\hline Child mentioned and age estimated on basis of weight & Children $>30 \mathrm{~kg}: 10 \mathrm{mg}$ per day & $13(9.9)$ & $130(0.2)$ \\
\hline Summary of product characteristics not available & & $14(1.0)$ & $78(0.1)$ \\
\hline
\end{tabular}

scriptions and were mainly dermatological and liquid preparations.

The table shows the official labelling of drugs prescribed for children. In $21.3 \%$ of the prescriptions for licensed drugs, use in children was not mentioned in the summary, and $19.7 \%$ mentioned use in children but without any indication of age. Although the summaries of remaining drugs indicated age, children were often divided into just two age groups.

Overall, 22.7\% (15 453) of the prescriptions for children were used off label. Drug groups with the highest percentages of off label use were urologicals or sex hormones (mainly oral contraceptives; 85.9\%), ophthalmological and otological drugs (79.4\%), dermatological drugs (55.9\%), and cardiovascular drugs (48.3\%). In the group with the highest number of prescriptions-respiratory drugs- $16.1 \%$ of all prescriptions were used off label.

\section{Comment}

Many licensed drugs used by children in the community are poorly labelled for use in children, resulting in high percentages of off label use. Therefore labelling for children needs to be improved, with the support of everyone working in pharmacotherapy.

Contributors: ES and HT were involved in the design, analysis, interpretation, and writing of the manuscript. LTWdJ-vdB supervised the design and execution of the study and contributed to the writing of the manuscript and will act as guarantor for the paper.

Funding: None.

Competing interests: None declared.

1 Turner S, Longworth A, Nunn AJ, Choonara I. Unlicensed and off-labe drug use in paediatric wards: prospective study. BMJ 1998;318:343-5.

2 tJong GW, Vulto AG, De Hoog M, Schimmel K, Tibboel D, van den Anker JN. Unapproved and off label use of drugs in a children's hospital. $N$ Engl JMed 2000;343:1125.

3 Conroy S, Choonara I, Impicciatore P, Mohn A, Arnell H, Rane A, et al. Survey of unlicensed and off label drug use in paediatric wards in European countries. BMJ 2000;320:79-82.

4 Chalumeau M, Tréluyer JM, Salanave B, Assathiany R, Chéron G, Chrocheton N, et al. Off-label and unlicensed drug used among French office based paediatricians. Arch Dis Child 2000;83:502-5.

5 McIntyre J, Conroy S, Avery A, Corns H, Choonara I. Unlicensed and offlabel prescribing of drugs in general practice. Arch Dis Child 2000;83:498-501.

(Accepted 4 October 2001)

\title{
Unlicensed and off label prescription of drugs to children: population based cohort study
}

\author{
Geert W 't Jong, Ingo A Eland, Miriam C J M Sturkenboom, John N van den Anker, \\ Bruno H Ch Stricker
}

Drugs are subject to licensing procedures to ensure their quality, efficacy, and safety, but many drugs used to treat children in hospital are either not licensed for use in children ("unlicensed") or are prescribed outside the terms of the product licence ("off label"). ${ }^{1}$ Little is known about such prescribing in general practice, so we conducted a cohort study in primary care in the Netherlands to investigate the subject.

\section{Methods and results}

We retrieved data from the integrated primary care information project, a longitudinal observational database containing information from computer based patient records of 150 general practitioners in the Netherlands. The system complies with European Union guidelines on the use of medical data for medi- cal research and has been proved valid for pharmacoepidemiological research. ${ }^{2}$

Within the dynamic population of children (0-16 years) registered in 1998, we conducted a one year population based cohort study. From a source population of 53702 eligible children, we randomly sampled $25 \%$ ( $\mathrm{n}=13426 ; 6941$ (51.7\%) boys), which formed our final study population. During the year 8271 (61.6\%) children consulted their general practitioner at least once; the median was one consultation a year. We classified all 17453 drug prescriptions issued to 6141 (45.7\%) children according to the licensing status of the drug, ${ }^{1}$ by reference to the official product licence, as provided by the Dutch Medicines Evaluation Board.

Seventy one per cent (12 405) of prescriptions were for drugs licensed for use in children and prescribed in agreement with the product licence. Of the remaining $5048(28.9 \%)$ prescriptions, 2667 (15.3\%, 95\% confi- 